\title{
Proliferative Activity of Healthy and Degenerated Intervertebral Disc Cellls in vitro Under Bone Morphogenetic Proteins' Influence: Implications tor Cell therapy
}

DOI: $10,17691 / \mathrm{stm} 2018,10.2 .08$

Received January 21, 2018

L.A. Bardonova, PhD Student, Neurosurgery Course";

E.G. Belykh, MD, Assistant, Neurosurgery Course';

M.B. Giers, PhD, Assistant Professor, Department of Chemical, Biological, and Environmental Engineering2;

M.C. Preul, Professor, Director, Neurosurgery Research Laboratory3;

V.A. Byvaltsev, MD, DSc, Professor, Head of the Neurosurgery Course'; Professor, Department of Traumatology,

Orthopedics, and Neurosurgery4; Head of the Scientific and Clinical Unit of Neurosurgery5;

Chief of the Neurosurgery Center ${ }^{6}$

${ }^{1}$ Irkutsk State Medical University, 1 Krasnogo Vosstaniya St., Irkutsk, 664003, Russia;

2Oregon State University, 1500 SW Jefferson St., Corvallis, OR, 97331, USA;

${ }^{3}$ Department of Neurosurgery Research, Barrow Neurological Institute, 350 W Thomas Rd., Phoenix, AZ, 85013, USA;

${ }^{4}$ Irkutsk State Medical Academy for Postgraduate Education - Branch of the Russian

Medical Academy of Continuing Professional Education of the Ministry Healthcare

of the Russian Federation, 100 Yubileyny Microdistrict, Irkutsk, 664049, Russia;

${ }^{5}$ Irkutsk Scientific Center of Surgery and Traumatology, 1 Bortsov Revolutsii St., Irkutsk, 664003, Russia;

${ }^{6}$ Railway Clinical Hospital at the Irkutsk-Passagirsky Station, 10 Botkin St., Irkutsk, 664005, Russia

The aim of the study was to evaluate the effect of bone morphogenetic proteins (BMP) on the proliferative activity of healthy and degenerated cells of the intervertebral disc (IVD) in vitro.

Materials and Methods. Cells obtained from the human annulus fibrosus and the nucleus pulposus of healthy and degenerated intervertebral discs were cultured in the absence and presence of BMP-2, BMP-7, and BMP-14. A daily cell count was performed using micrographs obtained by phase contrast microscopy and the Fiji program. On day 4, cells were fixed and stained with Alexa Fluor 633 phalloidin (for F-actin) and DAPI (for nuclear DNA), and imaged using laser confocal microscopy. The rate of cell growth was calculated at their exponential growth phase by mathematical modeling.

Results. In the presence of BMP-2, 7, and 14, insignificant changes in the growth rates of cells from the annulus fibrosus and the nucleus pulposus of the IVD (both healthy and degenerated) were noted. Changes in the proliferative activity were found in healthy cells of the annulus fibrosus supplemented with BMP-2, 7, and 14 ( $p<0.01$ ), and also in degenerated cells of the nucleus pulposus in the presence of BMP-14 $(p<0.01)$. Proliferative activity of degenerated cells from the nucleus pulposus was reduced in comparison with healthy cells $(p=0.03)$, while in annulus fibrosus cells there was no significant difference between the two compared groups. The addition of BMP did not restore proliferative activity of cells from the degenerated nucleus pulposus to the level of healthy cells. Morphological characteristics of the cells were similar: both, the nucleus pulposus cells and the annulus fibrosus cells resembled fibroblasts by having spread-eagle, stellate, spindle-like shapes with long protrusions.

Conclusion. Minor changes in the proliferative activity of IVD cells co-incubated with BMP-2, 7, and 14 were observed. Bone morphogenetic proteins had no significant effect on proliferation of IVD cells, which can be regarded as a positive factor under conditions of nutrient deficiency and reduced nutrient transport in the disc. The observed differences in growth rate between the nucleus pulposus cells and the annulus fibrosus cells may be due to different degrees of tolerance to degeneration or reflect the predominant role of the nucleus pulposus' in the cellular degeneration of the IVD.

Key words: intervertebral disc; degeneration of the intervertebral disc; bone morphogenetic protein; cell proliferation; cellular therapy.

\section{Introduction}

Degeneration of the intervertebral disc (IVD) is a complex process, which includes changes in IVD nutrition, decreased cell viability and cellularity, quantitative and qualitative changes in the extracellular matrix and the disc biomechanics [1]. It remains, however, unclear which of these processes are

Corresponding author: Vadim A. Byvaltsev, e-mail: byval75vadim@yandex.ru 
primary and which ones are secondary. Moreover, the IVD degeneration is, for a great part, a genetically determined process $[2,3]$. The complexity of the involved pathophysiological mechanisms makes it difficult to search for potential therapeutic targets and to rationalize the means of biological correction.

Conservative treatment of IVD degeneration is mainly aimed to manage acute pain; this treatment is largely symptomatic and has a short-lived effect. Surgery is usually recommended at the severe stages of IVD degeneration; this involves the risks of invasive intervention and in some cases causes adjacent segment degeneration due to spinal biomechanical changes [4]. At present, a promising area of research is biological approaches for IVD degeneration, especially, the therapy with growth factors, gene therapy, cellular therapy and tissue engineering $[5,6]$. One of the actively studied strategies of biological correction of mild IVD degeneration is the therapy with growth factors. Specifically, the superfamily of the transforming growth factor beta (TGF- $\beta$ ) consists of proteins that are believed to be related to the synthesis of collagen and proteoglycans and play an important role in the accumulation of the extracellular matrix. The TGF- $\beta$ family also includes bone morphogenetic proteins (BMP): BMP-2, BMP-7, and BMP-14 [7, 8]. At mild stages of the degenerative process, the growth factors stimulate the expression of the extracellular matrix components via the functionally active IVD cells, which can later restore the structure and function of the disc $[6,9]$. The efficacy of this therapy depends on the availability of a sufficient number of viable cells [10].

The aim of the study was to evaluate the effects of bone morphogenetic proteins on the proliferative activity of healthy and degenerated IVD cells in vitro.

\section{Materials and Methods}

Study design. Cell cultures from the annulus fibrosus (AF) and the nucleus pulposus (NP) of the human IVD were used.

Cells (Sciencell Research Laboratories, USA) originated from AF and NP of a healthy donor who had no spinal disorders were used to model healthy IVD cells. The cells were thawed in a water bath at $37^{\circ} \mathrm{C}$ and cultured in monolayer in sterile flasks with a surface area of $25 \mathrm{~cm}^{2}$ in a culture medium consisting of $89 \%$ of Dulbecco's Modified Eagle's Medium/F-12 medium (Thermo Fisher Scientific, USA) supplemented with $10 \%$ fetal bovine serum (FBS) (Life Technologies, USA) and $1 \%$ penicillin/streptomycin solution (Sigma, USA) at $37^{\circ} \mathrm{C}, 95 \%$ humidity and $5 \% \mathrm{CO}_{2}$.

Cells of degenerated IVD were isolated from tissue biopsies of AF and NP taken from patients undergoing a normal discectomy or fusion procedure on the lumbar spine.

The study was conducted in accordance with the Helsinki Declaration (2013) and approved by the Ethics
Committee of the Irkutsk State Medical University. An informed consent had been obtained from each patient.

The inclusion criteria were: a degenerative-dystrophic disease of the IVD with the stage II to IV degeneration as defined by the Pfirmann classification [11], the age of patients - from 18 to 65 years, the presence of severe pain in the lower back, and the lack of effect of conservative therapy for more than 4 weeks.

The exclusion criteria were: previous surgical interventions in the lumbosacral spine, the use of chemotherapy drugs, previous radiotherapy of the spine area, scoliosis, and diabetes mellitus.

Immediately after surgical extraction, fragments of IVD were placed in the medium (89\% Dulbecco's Modified Eagle's Medium/F-12, $10 \%$ FBS and $1 \%$ penicillin/streptomycin solution) and delivered to the laboratory. The tissues of NP and AF were carefully separated from each other, washed in sodium phosphate buffer (PBS) with $5 \%$ penicillin/streptomycin. Using the enzymatic disaggregation technique [12], the tissues were mechanically ground, incubated in a $0.24 \%$ solution of pronase (Sigma, USA) for $1 \mathrm{~h}$ and then in a $0.05 \%$ solution of type II collagenase (Sigma, USA) for $6 \mathrm{~h}$ at $37^{\circ} \mathrm{C}$. The collagenase solution with suspended cells was passed through a nylon filter with a pore diameter of $70 \mu \mathrm{m}$ (Thermo Fisher Scientific, USA). The cells were then washed twice in the medium and centrifuged at $150 \mathrm{~g}$ for $10 \mathrm{~min}$. The cell pellet was explanted into a medium-filled culture flask with a surface area of $25 \mathrm{~cm}^{2}$ and cultured at $37^{\circ} \mathrm{C}, 95 \%$ humidity, and $5 \% \mathrm{CO}_{2}$.

The medium was replaced every two days. After 5 days in the culture, a continuous layer of cells covered $85-90 \%$ of the flask surface. The cells were treated with $0.25 \%$ trypsin solution (GE Healthcare Life Sciences, USA) and then transferred to Petri dishes with a diameter of $35 \mathrm{~mm}$ with a bottom-embedded cover glass of $1.5 \mathrm{~mm}$ thick and $10 \mathrm{~mm}$ wide.

After the first passage, the cell lines of NP and AF were divided into 4 groups each: 1) cells grown in a medium supplemented with BMP-2 (Bone Morphogenetic Proteins Human Recombinant; ProSpec, USA); 2) cells grown in a medium supplemented with BMP-7; 3) cells grown in a medium supplemented with BMP-14; and 4) cells grown in a medium with no BMP (control medium). The media were renewed every two days. The above cell cultures were grown for 4 days.

Cell morphology and cell counts. Cell morphology was assessed by phase contrast microscopy using an inverted microscope with a green phase contrast filter (Axio Vert A1; Carl Zeiss, Germany). Digital images for further processing were obtained by photographing (a Canon camera with a magnification of 200) six optical fields in every culture dish. The photos were taken daily at the same time for 4 days. The obtained images were saved in the JPEG format. The digital images were processed and analyzed using the Fiji software $(\mathrm{NIH}$, USA) including a plug-in for cell counting [13].

After 4 days of culturing in media enriched with BMP- 
2,7 , and 14 , the cells were fixed in $4 \%$ paraformaldehyde solution, followed by staining with Alexa Fluor 633 phalloidin (Life Technologies, USA) specific for F-actin and with DAPI (NucBlue Fixed Cell ReadyProbes; Life Technologies, USA) for nuclear DNA; the slides were investigated using laser confocal microscopy (Zeiss LSM 7 Duo; Carl Zeiss, Germany).

Statistical processing was carried out using the Microsoft Excel and Statistica 9.0 software. The cell counts were normalized to plating density; the normalized cell count data were compared via the ANOVA criterion; the post-hoc t-test was applied to compare the independent groups. The differences between the means were considered statistically significant at $p<0.05$. All data was fit to the following cell growth model [14]:

$$
P=P_{0} e^{r t}
$$

where $P$ is the normalized population; $P_{0}$ - the initial normalized population; $r$ - the growth rate factor and $t$ - the time. In this study, the $P_{0}$ value was always 1 because we normalized the primary data. The statistical analysis also included the comparison of the cell growth rates and the correlation coefficients.

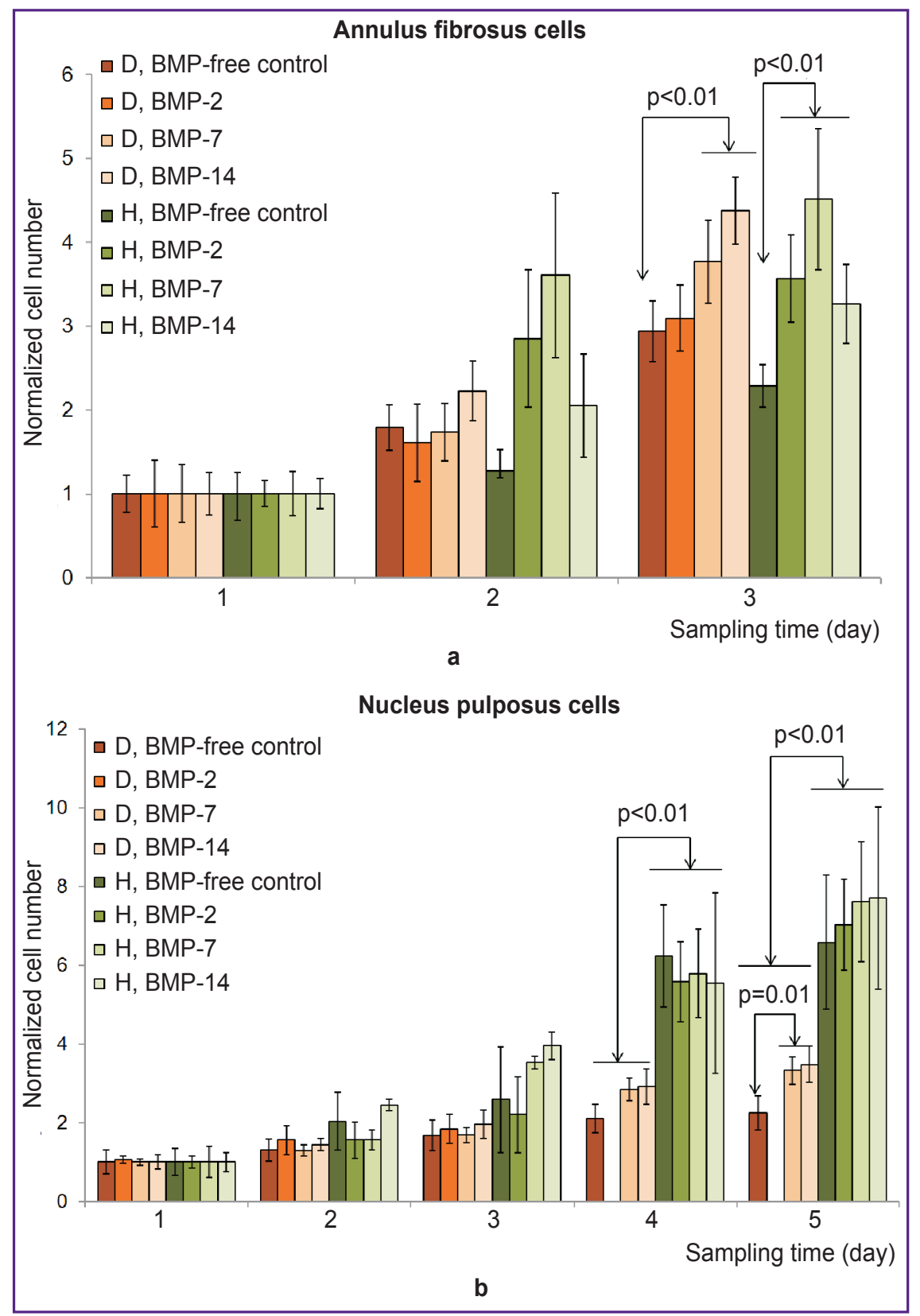

Figure 1. Normalized cell count values in healthy $(\mathrm{H})$ and degenerated (D) cell cultures:

(a) annulus fibrosus; (b) nucleus pulposus values are presented as mean \pm standard deviation

\section{Results and Discussion}

To account for the difference in the initial number of healthy cells at the stage of culture seeding, we normalized the results of cell growth per the initial density of the cell cultures.

During the four consecutive days of the experiment, an increase in the number of NP cells was observed (from $p=0.01$ to $p=0.04$ ). For the AF cell culture, a growth was noted for the first two days only $(p<0.01)$; then a continuous cell layer was formed, which prevented any further culture growth due to contact inhibition. Because of that, we calculated the cell growth based on three days for AF cells and on five days for NP cells (Figure 1).

The cell growth rate was calculated based on the normalized number of cells, which allowed us to determine the growth factors for cell populations. There were no significant differences in the proliferation coefficients between the degenerated and healthy AF cells $(p>0.9)$. At the same time, the proliferative activity of degenerated NP cells was significantly reduced in comparison with healthy NP cells $(p=0.03)$. The values of the growth factors of healthy and degenerated IVD cells are presented in the Table.

A comparison of cell growth in all cultures with the ANOVA test revealed no significant effect of any type of BMP on the proliferation of healthy cells $(p=0.17)$, while the BMP-containing media did have a significant effect $(p<0.01)$ on the degenerated cells from both NP and AF (see Figure 1). 
Proliferation coefficients of degenerated and healthy cells from the nucleus pulposus and the annulus fibrosus in the absence and presence of bone morphogenetic proteins (BMP)

\begin{tabular}{lcccc}
\hline Culture medium & \multicolumn{2}{c}{ Degenerated cells } & \multicolumn{2}{c}{ Healthy cells } \\
\cline { 2 - 5 } & $\begin{array}{c}\text { Annulus } \\
\text { fibrosus }\end{array}$ & $\begin{array}{c}\text { Nucleus } \\
\text { pulposus }\end{array}$ & $\begin{array}{c}\text { Annulus } \\
\text { fibrosus }\end{array}$ & $\begin{array}{c}\text { Nucleus } \\
\text { pulposus }\end{array}$ \\
\hline BMP-free control & 0.36 & 0.17 & 0.21 & 0.39 \\
\hline BMP-2 & 0.36 & 0.2 & 0.42 & 0.36 \\
\hline BMP-7 & 0.39 & 0.22 & 0.51 & 0.4 \\
\hline BMP-14 & 0.46 & 0.24 & 0.36 & 0.42 \\
\hline BMP-free control & 0.93 & 0.91 & 0.68 & 0.84 \\
\hline BMP-2 & 0.91 & 0.87 & 0.76 & 0.86 \\
\hline BMP-7 & 0.91 & 0.87 & 0.75 & 0.89 \\
\hline BMP-14 & 0.93 & 0.92 & 0.8 & 0.92 \\
\hline
\end{tabular}

In comparison with the control group (BMP-free), there was a slight increase in the growth of AF healthy cells in the presence of any BMP $(p<0.01)$. Notably, the degenerated AF cells showed an increase in their proliferation only in the presence of BMP-14 $(p<0.01)$. There was no significant effect of any BMP on the growth of healthy NP cells $(p=0.51)$, whereas BMP-7 and BMP-14 significantly increased the number of cells in the degenerated NP cell culture $(p=0.01)$.

After the immunocytochemical staining for the actin cytoskeleton, both the NP and AF cells, extracted from either healthy and degenerated IVDs, had similar morphological features (Figure 2). At 100\% confluence, the cells from AF and NP had similar spindle-like shapes with either longitudinal orientation or radial orientation (toward the center of cell accumulation). Cells in the cultures that did not reach complete confluence had an elongated or stellate shape with 3-4 processes, sometimes spindle-shaped. Part of the NP cells and some of the AF cells had long thin processes; those in the NP cells were much longer than those in the AF cells, sometimes reaching $250 \mu \mathrm{m}$ in length. The actin-associated cytoskeleton was well expressed; microfilaments were located evenly over the entire area of the cell, closer to the protrusions. Near the cell edge, the actin filaments formed intensely colored lumps, indicating the process of actin assembling in the area of protrusions. The cell nuclei looked flat and oval, about $15-30 \mu \mathrm{m}$ in diameter.

Thus, in this study, the proliferative activity of NP and AF cells grown with BMP-2, BMP-7, and BMP-14 was compared with the BMP-free control. Previous studies have shown [15] that BMP-2 stimulates the production of the extracellular matrix, in particular, the synthesis of proteoglycans. BMP-7 is also known as "osteogenic
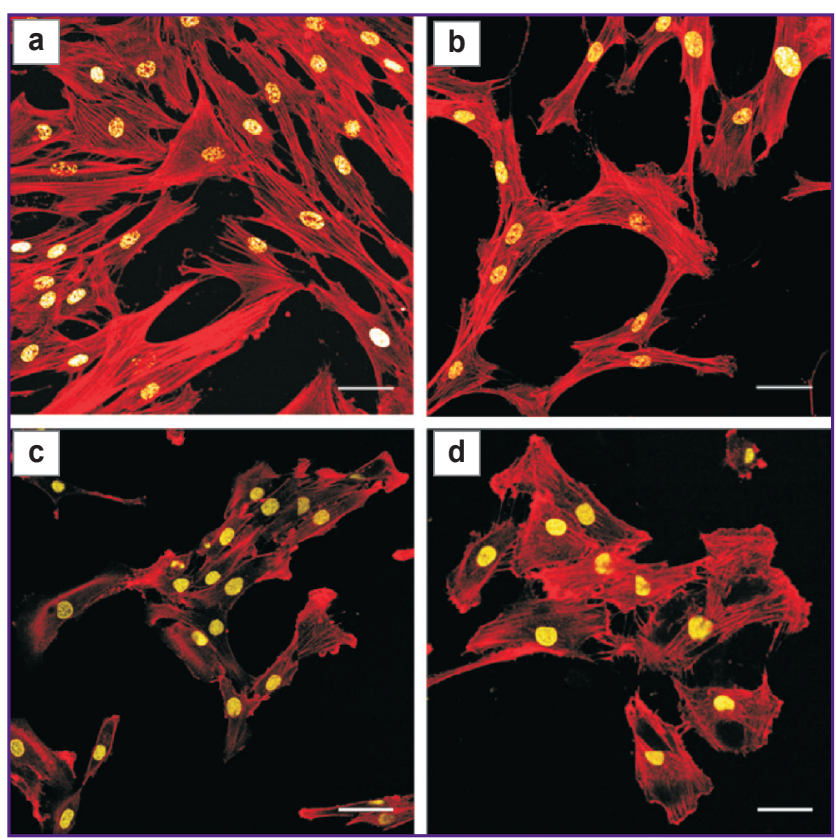

Figure 2. Immunocytochemical staining. Cells from the annulus fibrosus and the nucleus pulposus of healthy ( $a$ and b, respectively) and degenerated (c and $d$, respectively) intervertebral discs from 4-day cultures are shown

Staining for F-actin (Alexa Fluor 633 phalloidin, in red) and for nuclear DNA (DAPI, in yellow); images are made using laser scanning microscopy (scale bar $-50 \mu \mathrm{m}$ )

protein 1" and, like BMP-2, is used to activate the osteosynthesis during spinal fusion surgery and other orthopedic interventions [16]. Likewise, BMP-7 also showed the potential of stimulating the production of the extracellular matrix in the IVD [17]. BMP-14 (otherwise known as growth differentiation factor 5), another member of the TGF- $\beta$ family, has a stimulating effect on IVD cells, increasing the synthesis of proteoglycans and the expression of collagen type 2 [18].

In searching for the solutions to the nutrient deficiency in the IVD, the current and future approaches to regenerative therapy should consider both the number of cells and their nutritional demands. In this study, we found that BMP-2, 7, and 14 had no significant effect on the proliferation of healthy cells from NP, yet slightly increasing the proliferation of degenerated NP and $\mathrm{AF}$ cells.

\section{Conclusion}

In this in vitro study on cells from the nucleus pulposus and the annulus fibrosus of the intervertebral disc, small but statistically significant changes in cell proliferation were detected in the presence of bone morphogenetic proteins - BMP-2, 7, and 14. Culturing of degenerated cells from the nucleus pulposus in the presence of BMP did not increase their proliferative activity to the level of 
healthy cells. Along with that, the proliferative activities of healthy and degenerated cells from the annulus fibrosus were close to each other. Bone morphogenetic proteins had no significant effect on proliferation of intervertebral disc cells, which can be considered positive under the conditions of nutritional deficiency and reduced nutritional transport in the disk. These differences in the growth rates between the nucleus pulposus cells and the annulus fibrosus cells may indicate different tolerance to degeneration between various cell populations of the IVD and/or the predominant role of the nucleus pulposus" in degeneration of the intervertebral disc.

Financial support. This study was supported by a grant from the Russian Science Foundation (project No.15-15-30037) and the RF President's scholarship SP-2545.2018.4.

Conflict of interest. The authors declare no conflicting interests that could impact their work.

\section{References}

1. Evans C. Potential biologic therapies for the intervertebral disc. J Bone Joint Surg Am 2006; 88(Suppl 2): 95-98, https://doi.org/10.2106/jbjs.e.01328.

2. Virtanen I.M., Karppinen J., Taimela S., Ott J., Barral S., Kaikkonen K., Heikkilä O., Mutanen P., Noponen N., Männikkö M., Tervonen O., Natri A., Ala-Kokko L. Occupational and genetic risk factors associated with intervertebral disc disease. Spine 2007; 32(10): 1129-1134, https://doi. org/10.1097/01.brs.0000261473.03274.5c

3. Martirosyan N.L., Patel A.A., Carotenuto A., Kalani M.Y., Belykh E., Walker C.T., Preul M.C., Theodore N. Genetic alterations in intervertebral disc disease. Front Surg 2016; 3: 59, https://doi.org/10.3389/fsurg.2016.00059.

4. Maldonado C.V., Paz R.D., Martin C.B. Adjacent-level degeneration after cervical disc arthroplasty versus fusion. Eur Spine J 2011; 20(Suppl 3): 403-407, https://doi.org/10.1007/ s00586-011-1916-1.

5. Kepler C.K., Anderson D.G., Tannoury C., Ponnappan R.K. Intervertebral disk degeneration and emerging biologic treatments. J Am Acad Orthop Surg 2011; 19: 543553, https://doi.org/10.5435/00124635-201109000-00005.

6. Moriguchi Y., Alimi M., Khair T., Manolarakis G., Berlin C. Bonassar L.J., Härtl R. Biological treatment approaches for degenerative disk disease: a literature review of in vivo animal and clinical data. Global Spine J 2016; 6(5): 497-518, https://dol.org/10.1055/s-0036-1571955.

7. Than K.D., Rahman S.U., Vanaman M.J., Wang A.C. Lin C.Y., Zhang H., La Marca F., Park P. Bone morphogenetic proteins and degenerative disk disease.
Neurosurgery 2012; 70(4): 996-1002, https://doi.org/10.1227/ neu.0b013e318235d65f.

8. Belykh E., Giers M., Bardonova L., Theodore N., Preul M., Byvaltsev V. The role of bone morphogenetic proteins 2, 7, and 14 in approaches for intervertebral disk restoration. World Neurosurg 2015; 84(4): 871-873, https://doi. org/10.1016/j.wneu.2015.08.011.

9. Masuda K., An H.S. Prevention of disc degeneration with growth factors. Eur Spine J 2006; 15(Suppl 3): S422S432, https://doi.org/10.1007/s00586-006-0149-1.

10. Vasiliadis E.S., Pneumaticos S.G., Evangelopoulos D.S., Papavassiliou A.G. Biologic treatment of mild and moderate intervertebral disc degeneration. Mol Med 2014; 20: 400-409, https://doi.org/10.2119/molmed.2014.00145.

11. Pfirrmann C.W.A., Metzdorf A., Zanetti M., Hodler J., Boos N. Magnetic resonance classification of lumbar intervertebral disc degeneration. Spine 2001; 26(17): 18731838, https://doi.org/10.1097/00007632-200109010-00011.

12. Chan L.K., Leung V.Y., Tam V., Lu W.W., Sze K.Y., Cheung K.M. Decellularized bovine intervertebral disc as a natural scaffold for xenogenic cell studies. Acta Biomater 2013; 9(2): 5262-5272, https://doi.org/10.1016/j. actbio.2012.09.005.

13. Schindelin J., Arganda-Carreras I., Frise E., Kaynig V., Longair M., Pietzsch T., Preibisch S., Rueden C., Saalfeld S., Schmid B., Tinevez J.Y., White D.J., Hartenstein V., Eliceiri K., Tomancak P., Cardona A. Fiji: an open-source platform for biological-image analysis. Nat Methods 2012; 9(7): 676-682, https://doi.org/10.1038/nmeth.2019.

14. Bardonova L.A., Belykh E.G., Byvaltsev V.A., Theodore N., Preul M.C., Giers M.B. Mathematical model of bone morphogenetic proteins' influence on intervertebral disc cell proliferation in vitro. New Armenian Medical Journal 2017; 11(11): 55-60.

15. Kim H., Lee J.U., Moon S.H., Kim H.C., Kwon U.H., Seol N.H., Kim H.J., Park J.O., Chun H.J., Kwon I.K., Lee H.M. Spine 2009; 34: 1834-1838, https://doi.org/10.1097/ brs.0b013e3181ae18ba.

16. Lo K.W., Ulery B.D., Ashe K.M., Laurencin C.T. Studies of bone morphogenetic protein-based surgical repair. Adv Drug Deliv Rev 2012; 64(14): 1277-1291, https://doi.org/10.1016/j. addr.2012.03.014.

17. Imai Y., Miyamoto K., An H.S., Thonar E.J., Andersson G.B., Masuda K. Recombinant human osteogenic protein-1 upregulates proteoglycan metabolism of human anulus fibrosus and nucleus pulposus cells. Spine 2007; 32(12): 1303-1310, https://doi.org/10.1097/ brs.0b013e3180593238

18. Li X., Leo B.M., Beck G., Balian G., Anderson G.D. Collagen and proteoglycan abnormalities in the GDF-5deficient mice and molecular changes when treating disk cells with recombinant growth factor. Spine 2004; 29(20): 22292234, https://doi.org/10.1097/01.brs.0000142427.82605.fb. 